\title{
Assessing the Value of Subsidizing Large CHP Plants
}

\author{
Kārlis Baltputnis, Zane Broka, Antans Sauhats \\ Institute of Power Engineering \\ Riga Technical University \\ Riga, Latvia \\ karlis.baltputnis@rtu.lv, zane.broka@rtu.lv, sauhatas@eef.rtu.lv
}

\begin{abstract}
This paper explores the impact of large natural-gasfired combined heat and power plants on electricity price in the Latvian bidding area of the Nord Pool power exchange. While these power plants sell the electricity generated in an energyonly market, they also benefit from state aid in the form of capacity payments. Therefore, the financial feasibility of their continued operation with varying degrees of support is also explored. The case study is based on the two largest cogeneration plants in Latvia which are both recipients of capacity payments. It was found that the participation of these plants in the dayahead market can have a limiting effect on the electricity price in the Latvian bidding area; however, the support awarded to both power plants can be reduced while still maintaining their competitiveness in the energy-only market.
\end{abstract}

Index Terms--capacity payment, CHP, electricity market, longterm modeling, state support.

\section{INTRODUCTION}

Several European countries have established support mechanisms for certain categories of electricity producers. There are primarily two reasons for this - increasing the share of renewable generation in the national portfolio and ensuring generation adequacy.

The latter is of particular importance in power systems that operate under energy-only electricity markets. Large power plants necessary for system reliability are often incapable of recouping their investments as the market price does not cover all of their marginal and fixed costs. It both puts the continued operation of current peak plants at risk and hinders investments in new reliable and flexible capacities which are necessary as backup generation to renewables [1]-[3].

On the one hand, capacity payments have been identified as an effective way to promote new gas-fired generators and prevent the mothballing of existing ones [4]. Furthermore, they have also been linked to electricity price spike reduction [2], [5]. On the other hand, capacity mechanisms are also viewed as problematic due to the risk of market distortions [6]. Consequently, the European Parliament has expressed in 2015 that "national capacity mechanisms should only be used as a last resort, once all other options have been considered" [7].

Support schemes for renewables and cogeneration in Latvia have been implemented since the mid-1990s and continued with several amendments until 2012 after which no new beneficiaries are accepted in the scheme [8]. However, support granted to the power plants before the moratory is continued for up to 20 years depending on the generation technology. E.g., the large cogeneration plants studied in this paper have been granted the support for 15 years since commissioning. It is estimated that the total support costs for all types of power plants under the current scheme will comprise around 4 billion EUR up to 2037 [8].

The support for renewables and cogeneration is largely covered by all final electricity users in Latvia as a levy on their energy bills. It forms a relatively large cost burden to customers, particularly to energy-intensive industries, and results in a noncompetitive final price of electricity comparing to other European countries in the region. This, along with the huge pressure from the society, has forced the responsible authority, the Ministry of Economics of Latvia, to reconsider the amount of support and has served as the main motivation for this study.

Similarly to other Northern European countries, there is a significant presence of district heating $(\mathrm{DH})$ networks in Latvia. Meanwhile, support to cogeneration plants amounts to a significant part of the national support scheme. Consequently, as a first remedy to reducing the support payments, two highefficiency combined heat and power (CHP) plants in Riga were considered - CHP-1 (144 $\left.\mathrm{MW}_{\mathrm{el}}\right)$ and CHP-2 $\left(881 \mathrm{MW}_{\mathrm{el}}\right)$. These plants comprise $\sim 35 \%$ of the total installed generation capacity in Latvia [9] and were first awarded state support in 2007. The support continues until 2021 for CHP-1 and until 2028 for CHP-2.

The Latvian transmission system operator (TSO) has already acknowledged the reliability and self-sufficiency value these plants bring [9]. Thus, our objective in this study was twofold: to assess the impact of the two CHP plants on the electricity wholesale price formation in Latvia through longterm modelling up to 2030 and to evaluate if support can be reduced without the risk of mothballing the power plants. A hypothesis is put forward that these plants are fundamental in restricting excessive price rise in the Latvian bidding area of Nord Pool. It is then verified through electricity market price simulations and techno-economic assessment of the feasibility of CHP operation with support payments reduced to a varying degree.

The work presented in this paper has been co-financed by the National Research Program LATENERGI (2014-2017). 


\section{Methodology}

\section{A. Modelling Approach}

To quantitively assess the impact of both CHP plants on the day-ahead market clearing price, a market simulation model was devised (Fig. 1). The model includes approximated bids of all types of power plants in the considered bidding areas and a more accurate production model of the Riga CHP plants to enable detailed techno-economic feasibility calculations.

The algorithm is comprised of three main steps:

1) read the input data for a particular year;

2) model the supply-demand equilibrium to estimate the market clearing price for each hour of the year as follows:

a) consumption, non-fossil generation and interconnector power flow time series are used as input based on historical data and future assumptions;

b) local fossil sources, including Riga CHP plants, are activated in a step-wise manner based on their marginal costs until the demand is met;

3) techno-economic assessment of Riga CHP plant operation using the estimated cashflow of both power plants based on their hourly schedule throughout the year, fuel, electricity and heat prices, fixed costs and varying state support assumptions.

\section{B. CHP Production Model}

The case studied is carried out for the two largest CHP plants of Latvia, located in Riga and supplying heating energy to the DH network on the right bank of the city. Consequently, one of the main building blocks of the algorithm is the CHP production model to determine the hourly operation mode (cogeneration, condensing or mixed), amount of energy produced and the related short run marginal cost for each power unit of the plants. While the CHP-1 is solely a cogeneration plant, the CHP-2 is also capable of condensing and mixed mode operation when the electricity market price reaches a particular level. Additionally, both plants have hot water boilers to cover peak demand of heating during cold spells or to supply heating whenever the cogeneration mode is either technically or economically unfeasible.

The procedure to estimate the cost of energy produced starts with distribution of the heating load among the plants:

$$
Q_{\mathrm{CHP}-1}^{t}+Q_{\mathrm{CHP}-2}^{t}=k \cdot Q_{\Sigma}^{t}+(1-k) \cdot Q_{\Sigma}^{t},
$$

where $Q_{\Sigma}^{t}$ - total heat demand (MWh) during hour $t ; Q_{\mathrm{CHP}-1}^{t}$, $Q_{\mathrm{CHP}-2}^{t}-$ heat load to be covered by each plant (MWh), and coefficient $k$ expresses the division of the heat load in the $\mathrm{DH}$ network.

The amount of electricity to be produced by each power unit $n$ of the CHP plants depends on the hourly heating load assigned to it, $Q_{n}^{t}$. Thus, the amount of electricity to be produced in cogeneration mode by power unit $n$ (MWh):

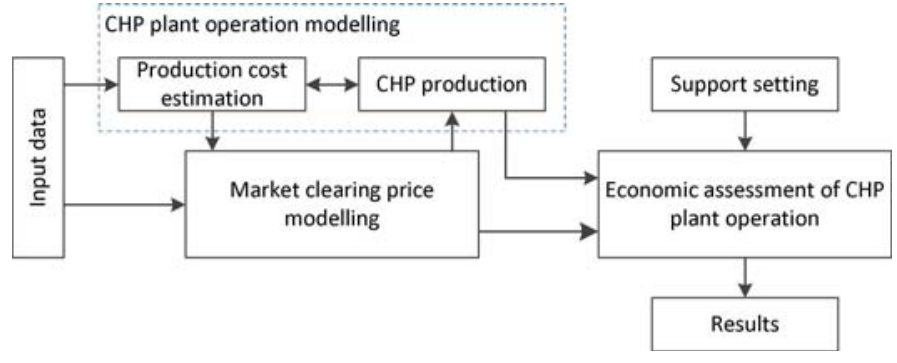

Figure 1. The overall structure of the model

$$
E_{n \text { cog. }}^{t}= \begin{cases}a_{n} \cdot Q_{n}^{t} \cdot A_{n}^{t} & \text { if } Q_{n \text { cog. }}^{\min } \leq Q_{n}^{t} \leq Q_{n \operatorname{mog} .}^{\max } \\ a_{n} \cdot Q_{n \text { cog. }}^{\max } \cdot A_{n}^{t} & \text { if } Q_{n}^{t}>Q_{n \operatorname{mog} .}^{\max } \\ 0 & \text { if } Q_{n}^{t}<Q_{n \text { cog. }}^{\min }\end{cases}
$$

where $a_{n}$-coefficient expressing the proportion of electricity production versus heat production, $A_{n}^{t}$ - binary variable designating the availability of power unit $n$ at hour $t, Q_{n \text { cog. }}^{\min }$ and $Q_{n \text { cog. }}^{\max }-$ technical constraints on the heat production in the power unit. Similar calculations are carried out also for the condensing and mixed operation modes of CHP-2.

The cost of electricity produced in any of the modes, $C_{n \mathrm{E}}^{t}$, is comprised of two main components: the cost of fuel and the cost of carbon emissions: $C_{n \mathrm{E}}^{t}=C_{n \mathrm{E}, \mathrm{G}}^{t}+C_{n \mathrm{E}, \mathrm{CO}_{2}}^{t}$, of which

$$
C_{n \mathrm{E}, \mathrm{G}}^{t}=\underbrace{E_{n}^{t} /\left(\eta_{n} \cdot Q_{\mathrm{LHV}}\right) \cdot G_{n}^{t}}_{G_{n \mathrm{E}}^{t}} \cdot c_{\mathrm{G}} \cdot 10^{-3},
$$

where $E_{n}^{t}$ - the amount of electricity produced (MWh), $\eta_{n}-$ power generation efficiency, $Q_{\mathrm{LHV}}$ - lower heating value of the fuel $\left(\mathrm{MWh} / \mathrm{nm}^{3}\right), G_{n}^{t}$ - total fuel (natural gas) consumption of the power unit $\left(\mathrm{nm}^{3}\right), G_{n \mathrm{E}}^{t}-$ fuel consumption for electricity production $\left(\mathrm{nm}^{3}\right), c_{G}-$ fuel price $\left(€ /\right.$ t. $\left.\mathrm{nm}^{3}\right)$, and

$$
C_{n \mathrm{E}, \mathrm{CO}_{2}}^{t}=\underbrace{G_{n \mathrm{E}}^{t} \cdot Q_{\mathrm{LHV}} \cdot f_{\mathrm{CO}_{2}}}_{E m_{n \text { cog. } \mathrm{E}}^{t}} \cdot c_{\mathrm{CO}_{2}}
$$

where $f_{\mathrm{CO}_{2}}-\mathrm{CO}_{2}$ emission factor (t/MWh), $E m_{n \text { cog. } \mathrm{E}}^{t}-\mathrm{CO}_{2}$ emissions from electricity production $(\mathrm{t}), c_{\mathrm{CO}_{2}}-$ cost of $\mathrm{CO}_{2}$ emission allowances $(€ / \mathrm{t})$.

Finally, the marginal cost of electricity (€/MWh) used for bidding to the market is determined for each operation mode:

$$
c_{n \mathrm{E}}^{t}=C_{n \mathrm{E}}^{t} /\left(E_{n}^{t}-E_{n \text { s.c. }}^{t}\right)
$$

where $E_{n \text { s.c. }}^{t}$ is the self-consumption energy of power unit (MWh). 


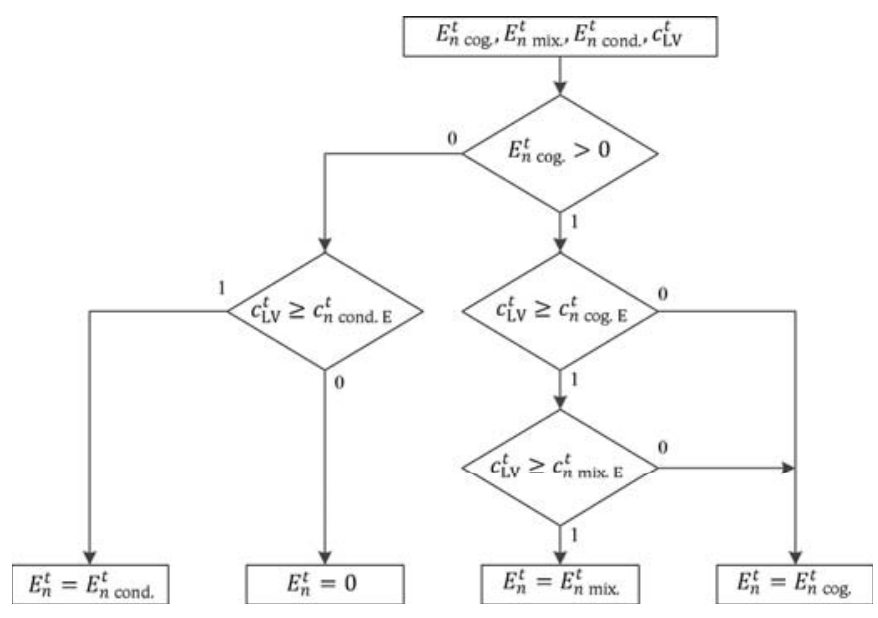

Figure 2. Decision logic for power generation mode selection of CHP plants

The resulting marginal costs along with the corresponding amounts of generation for all technically feasible modes of CHP plants are then passed to the overall market simulation model. The market clearing model outputs the wholesale price signal based on the established supply-demand equilibrium which is then compared to the marginal costs of the CHP plants to select the operational mode for each power unit as illustrated in Fig. 2. The variable $c_{\mathrm{LV}}^{t}$ represents the market clearing price in the bidding area where the CHP plants in question operate - in this case, it is the Latvian area of the Nord Pool.

\section{Main Assumptions and Input Data}

All the input data and assumptions used in this study were sourced from publicly available data.

The market clearing price is obtained through an indirect supply and demand curve simulation, where the demand curve is assumed to be price-inelastic as is the case in power systems without well-developed demand response programs [10].

The case study focuses on Latvia, thereby there are some assumptions that follow from local peculiarities. Firstly, the Latvian and Lithuanian bidding areas are modelled as one due to their well-developed interconnections. Secondly, several energy sources that otherwise would be modelled via optimal dispatch are implemented as non-dispatchable due to the support scheme (i.e., feed-in tariffs) in place in Latvia that demotivate the owners of small hydropower and cogeneration plants from planning their schedules following market signals.

All exogenous time series (production of small and intermittent plants from ENTSO-E Transparency Platform, consumption, electricity import price from other Nord Pool areas) are obtained by scaling historical data using April 2016 to March 2017 as the base year. Earlier data was not used as the market situation has changed significantly after NordBalt cable (LT-SE4) started its regular operation at the beginning of 2016. The choice of scaling factors, however, is scenario based. Also, historical data on unavailability of interconnectors from ENTSO-E Transparency Platform is used.

If import capacities are sufficient for covering the consumption in Latvia and Lithuania without activating additional local fossil units, the marginal price is assumed to be defined by import from the SE4 area of Nord Pool market. The assumption is based on the historic market trends and the price series for SE4 is derived from Energinet's future projections [11]. The same source is used for fuel and $\mathrm{CO}_{2}$ emission price projections for 2018-2030.

Additionally, the Kruonis pumped storage hydropower plant in Lithuania has been modelled to purchase electricity when its price is below $80 \%$ and sell when it is above $111 \%$ of the two-week average (due to the 0.72 round-trip efficiency of the plant). Table I summarizes the remaining local fossil plants [12] that can be activated in the model to meet the demand of electricity. The last entry in the table (a low efficiency oil plant) is the price setting one if consumption is not met otherwise, i.e., it is the final marginal unit, hence its max power is not constrained.

TABLE I. FOSSIL POWER PLANTS MODELLED IN THE MERIT ORDER LIST

\begin{tabular}{|l|c|c|c|c|c|c|c|}
\hline \multirow{2}{*}{ Parameter } & \multicolumn{7}{|c|}{ Type } \\
\cline { 2 - 8 } & \multicolumn{3}{|c|}{ Natural gas (cogeneration) } & $\begin{array}{c}\text { Natural gas } \\
\text { (condens.) }\end{array}$ & \multicolumn{2}{c|}{ Oil (condens.) } \\
\hline $\begin{array}{l}\text { Max. power } \\
\text { (MW) }\end{array}$ & 360 & 60 & 110 & 335 & 455 & 600 & - \\
\hline Efficiency & 0.915 & 0.9065 & 0.8087 & 0.7988 & 0.58 & 0.38 & 0.22 \\
\hline
\end{tabular}

Another important time series for the CHP production model is heating demand in the right bank of Riga. It is approximated by using public reports of Riga CHP-1 and -2 [13] and some additional assumptions. The hourly time series for the whole year is created by solving an error minimization problem on polynomial coefficients describing the heating load as a function of temperature during the heating season. During the summer, a constant demand of $81 \mathrm{MWh}$ is assumed approximated from the public data.

Overall, two different future scenarios have been considered for market simulations:

A. Conservative scenario. NordBalt disconnects as often as in the base year (only $72 \%$ availability), and Riga CHP plants supply all the heating load in the right bank of Riga.

B. Development scenario. NordBalt repairs have been concluded eliminating the frequent disconnections. To simulate that, we use EstLink-2 historical availability rate (95.7\%). Several new thermal plants commissioned in Riga decrease the load for the CHP-1 and -2 by $80 \mathrm{MW}_{\text {th }}$.

The remaining system assumptions are the same for both scenarios:

1) from 2021, the transmission capacity from Estonia to Latvia increased by $600 \mathrm{MW}$;

2) Riga CHP-1 decommissioned after 2021 as the state support period for it ends;

3) from 2025, the transmission capacity from Estonia to Latvia increased by $1400 \mathrm{MW}$;

4) Riga CHP-2 decommissioned after 2028 as the state support period for it ends.

The overall modelling approach was validated by modelling the year 2016. The actual average wholesale market price 
in 2016 was $36.09 € / \mathrm{MWh}$ but the weighted average $38.55 € / \mathrm{MWh}$. The results obtained from the model were $35.53 € / \mathrm{MWh}$ and $37.58 € / \mathrm{MWh}$ respectively. Thus, it was concluded the model is sufficiently accurate for its use in further studies.

\section{RESULTS AND DISCUSSION}

\section{A. Conservative Scenario}

The results from the conservative scenario are summarized in Fig. 3-5. The impact of Riga CHP plants on the electricity price is estimated by comparing modelling runs with and without their participation in the market.

Fig. 3 shows the price in SE4 as a reference for electricity imports and the simulated weighted average market price in Latvia. The price here is averaged over four different types of hours based on the availability of the NordBalt connection and Riga CHP plants. We see that in 2018, 2023 and 2028, the CHP plants contribute to a decrease of the price by 5.71, 12.74 and $29.65 € / M W h$ respectively during the hours when the NordBalt is operational and by $32.32,48.97$ and $82.45 € / \mathrm{MWh}$ respectively when it is not. The price limiting effect of the CHP plants is indeed the most prominent when the import link from Sweden is out of service.

When the price is averaged over the whole year, the unavailability of Riga CHPs causes an increase by 13.00, 22.77 and $44.26 € / \mathrm{MWh}$ in 2018, 2023 and 2030 respectively (Fig. 4). However, one should be wary of long-term prognosis as the degree of uncertainty increases the further in the future we model [14].

Increased electricity prices would put a strain on the national economy. We can estimate the overall escalation in costs by using the annual consumption of electricity. The total expenditure on electricity would increase by $95.44 \mathrm{M} €$ in 2018, by 175.27 M€ in 2023 and by 357.94 M€ in 2028 if Riga CHPs would not participate in the day-ahead market.

In Fig. 5 we can see the results of techno-economic assessment of the overall profitability of Riga CHP plants with different support schemes in mind. The capital costs and fixed annual costs of the power plants are sourced from public data, whereas the variable costs and income from the spot market are output by the model. $100 \%$ designation here corresponds to the full amount of support in effect for 2017. It provisioned capacity payments of $8525 € / \mathrm{MW} /$ month with a condition of operating at least for 1200 hours/year in cogeneration mode. Furthermore, starting with hour 1201, if the monthly income in the spot market was more than the marginal cost in any of the remaining months of the year, the support would be reduced by $75 \%$ of the monthly operational profit from the spot market [15].

Evidently, the support can be decreased to $75 \%$ of the current level without endangering the feasibility of continued power plant operation. If support is reduced to $50 \%$, the operation becomes feasible only starting from 2025 , but with $25 \%$ support it is only feasible in 2028 , i.e., in all previous years the plants would operate at a loss and thus would unlikely still be maintained. In case of immediate complete support withdrawal, the CHP plants would suffer a 73 M€ loss already in 2018.

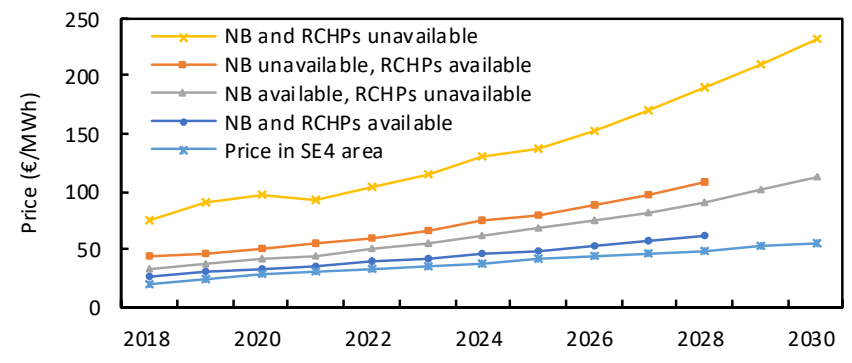

Figure 3. Annual weighted average electricity price in selected hours based on the availability of NordBalt and Riga CHP plants (conservative scenario)

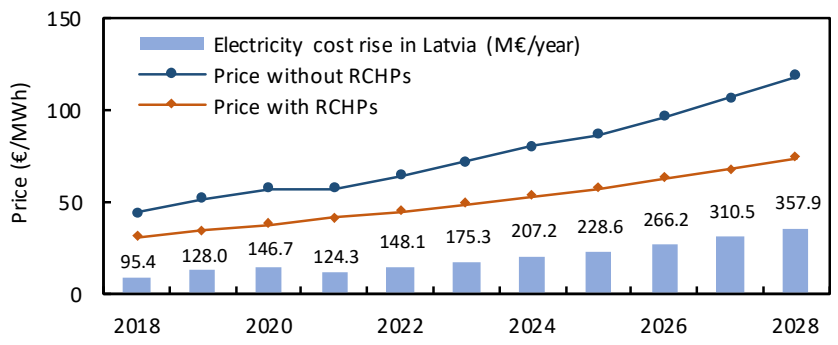

Figure 4. Weighted average electricity price of the whole year with/without Riga CHP plants and electricity cost rise w/o RCHPs (conservative scenario)

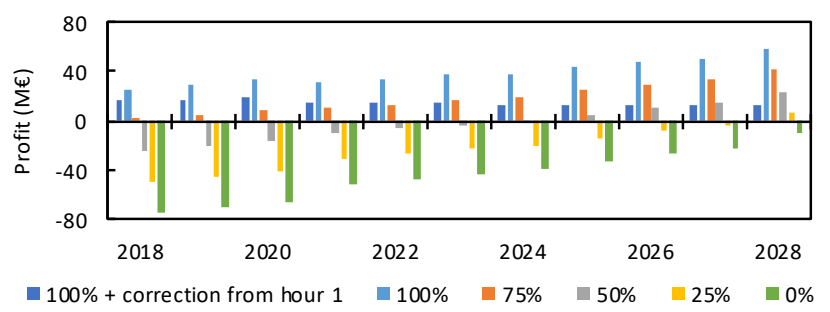

Figure 5. Profit of CHP plants with diff. amounts of support (cons. scen.)

Interestingly, the current amount of support with altered correction condition (from the $1^{\text {st }}$ hour instead of 1201) would allow to keep the profitability metrics reasonably positive (without exceeding $20 \mathrm{M€} /$ year) - the more favorable market conditions, the less support is necessary.

\section{B. Development Scenario}

When compared to the conservative scenario, this case envisions a slower electricity price increase due to more stable operation of the NordBalt cable (Fig. 6). For instance, if previously the weighted average price for 2018 was $30.95 € / \mathrm{MWh}$, then in this scenario it is merely $26.73 € / \mathrm{MWh}$.

The cost increase brought by the absence of CHP plants (Fig. 7) would be by 54-120 M€/year less than in the conservative scenario, but still quite significant $(41.69 \mathrm{M} €$ in 2018, 95.88 $\mathrm{M} €$ in 2023 and 238.09 $\mathrm{M} €$ in 2028).

The profitability in this scenario (Fig. 8) is more limited due to inability of the CHP plants to operate in the summer (because of the assumption of new heat sources outcompeting the large CHPs in district hot water provision) and close competition with imported electricity from Scandinavia. In the case of $75 \%$ support, the plants would operate at a loss till 2021. Any further support reduction would make the operation of CHP plants unfeasible. In the case of full support withdrawal, the plants would have an $85.5 \mathrm{M} €$ loss already in 2018. 


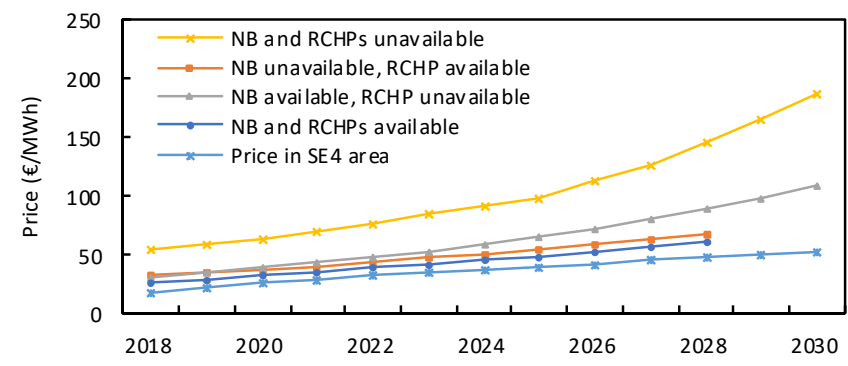

Figure 6. Annual weighted average electricity price in selected hours based on the availability of NordBalt and Riga CHP plants (development scenario)

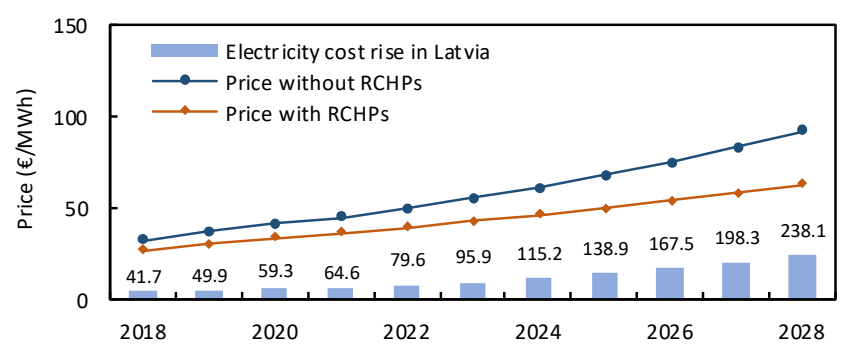

Figure 7. Weighted average electricity price of the whole year with/without Riga CHP plants and electricity cost rise w/o RCHPs (development scenario)

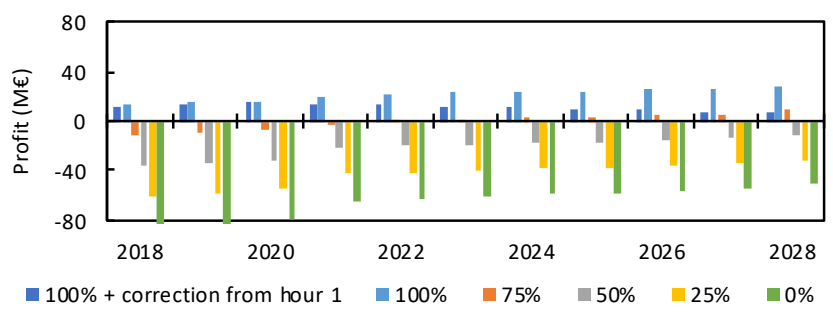

Figure 8. Profit of CHP plants with diff. amounts of support (dev. scen.)

\section{Discussion}

It becomes evident from the modelling results that decrease in state support to the Riga CHP plants to $50 \%$ of the current level or lower would significantly reduce the profitability and economic feasibility of continued power plant operation as they would be unable to cover the annual expenses.

However, reduction to $75 \%$ of the current level only shows negative financial metrics until 2022 in the development scenario and 2018 in the conservative scenario and would be well manageable in the later years.

The electricity and fuel price assumptions in Scandinavia used in the model envision favorable market conditions for natural gas plants in future years enabling them not only to cover variable costs but also to finance at least a part of the capital expenditure. Nevertheless, price projections up to ten years in the future have to be viewed with caution, especially since the price assumptions for the closest few years are based on futures contracts, but further developments are results of modelling [11]. Of course, the results of this study are input and assumption sensitive, but they are nevertheless useful in comparative terms. Overall, they do affirm the hypothesis of the significant role of Riga CHP plants in limiting the wholesale price of electricity, especially when other significant market infrastructure objects (e.g., the interconnector to Sweden) are disconnected.

\section{CONCLUSIONS}

The Riga CHP plants have a very important role in the Latvian power system not only in terms of generation selfsufficiency and reliability, but also in ensuring efficient electricity wholesale market operation by limiting excessive price rises. The absence of these power plants would result in significantly higher costs of electricity for all consumers.

On the other hand, the market situation at the moment is not favorable to natural gas cogeneration plants yet despite their high efficiency and comparatively low emissions. Hence, support schemes have to be applied to ensure continued availability of these large power plants.

However, evidently there is merit in reevaluating the amount of support these power plants receive. In our study, we identified options to decrease the support payments. The Ministry of Economics of Latvia has already taken these findings into account and has reduced the amount of support to a more reasonable level, thus decreasing the related levy on electricity bills of the energy end-users in Latvia.

\section{REFERENCES}

[1] F. Olsina, R. Pringles, C. Larisson, and F. Garcés, "Reliability payments to generation capacity in electricity markets," Energy Policy, vol. 73, pp. 211-224, Oct. 2014.

[2] T. Levin and A. Botterud, "Electricity market design for generator revenue sufficiency with increased variable generation," Energy Policy, vol. 87, pp. 392-406, Dec. 2015.

[3] N. Helisto, J. Kiviluoma, and H. Holttinen, "Sensitivity of electricity prices in energy-only markets with large amounts of zero marginal cost generation," in 2017 14th International Conference on the European Energy Market (EEM), 2017, no. 293437, pp. 1-6.

[4] D. Hach and S. Spinler, "Capacity payment impact on gas-fired generation investments under rising renewable feed-in - A real options analysis," Energy Econ., vol. 53, pp. 270-280, Jan. 2016.

[5] A. S. Ibanez-Lopez, J. M. Martinez-Val, and B. Y. Moratilla-Soria, "A dynamic simulation model for assessing the overall impact of incentive policies on power system reliability, costs and environment," Energy Policy, vol. 102, no. October 2016, pp. 170-188, Mar. 2017.

[6] European Parliamentary Research Service, "Capacity mechanisms for electricity," 2017.

[7] European Parliament resolution of 15 December 2015, "Towards a European Energy Union."

[8] European Commission, "State Aid SA.43140 (2015/NN) - Latvia Support to renewable energy and CHP," 2017.

[9] Augstsprieguma tīkls AS, "Annual statement of transmission system operator for the year 2016," 2017. [Online]. Available: http://ast.lv/files/ast_files/gadaparskzinoj/TSO_Annual_Statement_201 6.pdf.

[10] E. Bompard, R. Napoli, and B. Wan, "The effect of the programs for demand response incentives in competitive electricity markets," Eur. Trans. Electr. Power, vol. 19, no. 1, pp. 127-139, Jan. 2009.

[11] Energinet, "Energinet's analysis assumptions," 2016.

[12] A. Tkaczyk, J. Rekis, A. Auce, E. Urbonavicius, E. Norvaisa, and W. Jaworski, "BRILLIANT project: Required data for WP3 - Role of nuclear energy in long-term sustainable energy supply in the Baltic region," 2015

[13] Latvenergo AS, "Sustainability and Annual Report 2016," Riga, 2017.

[14] M. Yang, W. Blyth, R. Bradley, D. Bunn, C. Clarke, and T. Wilson, "Evaluating the power investment options with uncertainty in climate policy," Energy Econ., vol. 30, no. 4, pp. 1933-1950, Jul. 2008.

[15] Regulations Regarding Electricity Production and Price Determination upon Production of Electricity in Cogeneration. Latvian Cabinet of Ministers Regulation No 221 of 10 March 2009. 